\title{
A study to assess the effectiveness of play therapy on anxiety among hospitalized children
}

\author{
Kinjal Patel ${ }^{1}$, Suresh V ${ }^{2}$, Ravindra H.N. ${ }^{3}$, \\ ${ }^{1}$ Student, Sumandeep Nursing College, Sumandeep Vidyapeeth, Piparia, Vadodara-391760, Gujarat, India, \\ ${ }^{2}$ Associate Professor, Department of Mental health Nursing Sumandeep Nursing College, Sumandeep \\ Vidyapeeth, Piparia, Vadodara-391760, Gujarat, India, \\ , ${ }^{2}$ Principal,Sumandeep Nursing College, Sumandeep Vidyapeeth, Piparia, Vadodara-391760, Gujarat, India.
}

\begin{abstract}
Play promotes healing and helps the child to cope with stressful experiences. Children Won fear treatments are helped to release their feelings in their use of falls and other toys. The attitudes and feelings that children reveal in their play are full of meaning.. The child can find acceptable outlets for hostilities through play activities. The study aimed at to assess the pre test and post test level of anxiety among hospitalized children in selected hospitals at Vadodara, To evaluate the effectiveness of play therapy on anxiety among hospitalized children in selected hospitals at Vadodara, To determine the association between post-test anxiety level among hospitalized children in selected hospitals at Vadodara and demographic variables. The convenient sampling technique was used to select the sample for the study. Data was collected by using a structured anxiety rating score. The tool consists of two parts. First part consists of demographic data of the sample and second part consists of the a structured anxiety rating score In experimental post test mean score, 37.87 and SD was 14.708 respectively. The obtained 't' value 14.015 statistically was significant at 0.000 level. So research hypothesis was accepted, in Comparison of mean score of experimental post - test and control post test that the obtained ' $t$ ' value is 8.165 statistically $v$ a l u e was .000 so it is significant $(<0.05)$ therefore research hypothesis was accepted so it clearly shows that the level of anxiety was reduce in experimental group in post test The study concluded that children's was anxious in the pre-test and were as in the post-test shows that children's was not anxious or reduced so, it indicates that play activities was effective
\end{abstract}

Key Word: Anxiety, Emotional reaction, fear, Gaze behavior, Growth and Development, Hospitalization, Misconception, Play activities, Therapeutic value

\section{Introduction}

Hospitalization is stressful for children of all ages. During a serious illness, even older children have a great need for their parents and can tolerate their absence only for short periods. They need to know that their parents will be there when they need them most and that they are loved and missed.1

Play is an essential part of a child's life and is an important aspect in fostering growth and development. Toys are the "tools" of play and provide a more "natural" environment for a child. The proper selection and use of toys can reduce the traumatic effects of a hospitalization experiences and aid in the recovery phase of illness. ${ }^{1}$

Play is an integral part of the hospitalized child's plan of care. Play offers, the child an opportunity or creative expression, diversion and effective coping. In the hospital a supervised play program provides warm, friendly atmosphere that will help the child continue to grow and develop. In larger hospitals a child life specialist may coordinate the play program. A place to play, suitable materials and other children to play with are essential. Because play is a child's way of learning; toys, materials, and equipment are learning tools. ${ }^{2}$

Play promotes healing and helps the child to cope with stressful experiences. Children Won fear treatments are helped to release their feelings in their use of falls and other toys. The attitudes and feelings that children reveal in their play are full of meaning. Every opportunity should be afforded the hospitalized childe to use play and other expensive activities to lessen stress, thus promoting healthy resolution of the negative aspects of the hospital experiences. The child can find acceptable outlets for hostilities through play activities. ${ }^{3}$

The proper selection of toys can provide constructive, educational stimulating relaxing, diversional, or therapeutic value. Play is an essential element in the development of healthy individuals; childhood play is an integral part of the developmental process in young children. It occurs spontaneously in children and gives then an important medium for informal learning play is not a purposeless activity serving only to pass the childhood hours, it's a vital factor in intellectual, social, and emotional development of a child. ${ }^{4}$

The way a child most naturally express himself / herself is through their play. Often we find that the child who is confronted with a major life adjustment. Play therapy is designed to help children grow up as happy and well adjusted as possible. ${ }^{5}$ 
Play is the language of children. It's their most natural activity. Through play children express themselves, explore their world \& learn. Play can also be an important therapeutic intervention for children experiencing adjustment problems. Play therapy offers children a safe, natural and non-intrusive method of recovering from distressing life events. It can be useful intervention for children exhibiting a range of problematic behaviour such as regression, anxiety, extreme anger, aggression $\&$ fears. ${ }^{6}$

\section{Statement Of Problem}

"A study to assess the effectiveness of play therapy on anxiety among hospitalized children in selected hospitals at Vadodara".

\section{Objectives Of The Study}

1. To assess level of anxiety among hospitalized children before and after administering play therapy in experimental and control group.

2. To determine the effectiveness of play therapy among hospitalized children in experimental group.

3. To determine the association between post test anxiety level among hospitalized children and selected demographic variables such as age, sex and income of family.

\section{Hypothesis}

H1 - There will be significant difference on the level of anxiety among hospitalized children in selected hospitals at Vadodara between experimental and control group.

H2 - There will be a significant association between post-test of anxiety among hospitalized children and selected demographic variable such as age of child, sex of the child, birth order of the child, place of residence, type of family, income of family, religion, temperament of the child, previous exposure to the hospital, number of hospitalization within last one year, diagnosis, medical personnel in their family.

\section{Material And Method}

Research Approach: Quantitative research approach was used.

Research Design: Untreated control group design with pre test and post test or nonequivalent or four cell design, which belongs to quassi- experimental design was selected to assess anxiety of the hospitalized preschool children.

Setting Of The Study: The study was conducted in two selected hospital, may permitting at Vadodara.

SAMPLE: The sample for the present study comprises of 60 hospitalized children (30 - experimental group and 30- control group) who fulfilled the sampling criteria and expressed willingness to participate in the study

Sampling Technique: convenient sampling technique was used.

Development Of Tool For Data Collection: it consists of 2 parts:-

Part 1:- dealt with the demographic data of the sample

Part 2:- A structured anxiety rating scale was prepared consisting of 40 items on different areas about anxiety

Validity Of Instrument: To ensure content validity of the tool, the structured anxiety rating scale was send to 8 experts. The experts are selected based on their clinical expertise, experience and interest in the problem being studied. They are requested to give their opinions on the appropriateness and relevance of the items in the tool. The experts are from the field of nursing and medical. Modifications of items in terms of simplicity and order are made.

Reliability: In order to establish the reliability of the tool it is administered to 6 preschool children admitted in Chiranjeevi hospital at Vadodara. The structured anxiety rating scale reliability was established by using split half method and it was found to be $r=0.96$, which indicate that the tool was reliable.

Data Collection Procedure: The data collection on was carried out from $11^{\text {th }}$ November to $27^{\text {th }}$ November 2013. On day one the purpose of the study was explained to the mothers and an informed consent was taken before starting the study. A pre - test was conducted by Instructor Observation the selected 60 pre - school children on the basis of structured anxiety rating scale [experimental 30 and control 30] on the next day the Play activities was administered to the sample. The Play activities was continued period of 15 days and a conducted post-test by using the same structured anxiety rating scale on the 17th day. 


\section{Analysis Of Data}

Both descriptive and inferential statistics analyzed on the basis of the objectives and hypotheses of the study. Mean, median, range and standard deviation calculated. ' $t$ ' test is used to assess the significance of the difference between pre test and post test score would be determined. The analysis of variance (ANOVA) is used to find out the association between post test knowledge score and selected demographical variables. Data would be presented in the form of tables and graphs.

\section{Results}

The results were computed using descriptive and inferential statistics based on hypotheses and the objectives of the study.

\section{Presentation Of Data}

The descriptive and inferential statistics are used to analyze the data and are represented in the form of tables and diagrams. It is presented under the following headings

SECTION A: Description of demographic factors of children

SECTION B: Level of anxiety among hospitalized children in pre-test and post-test among experimental and control group.

SECTION C: Description of observational score on effectiveness of play therapy among hospitalized children SECTION D: association between selected demographic variables and anxiety

\section{Section A: Description Of Demographic Factors Of Children}

* In experimental group majority children $66.7 \%$ belongs to $3-4$ years of age and $33.3 \%$ of children belong $5-6$ years

In control group 50\% of children belongs to 3 - 4 years of age and 50\%, of children belongs to $5-6$ years

* $50 \%$ of the children belongs to males and $50 \%$ of them were females in experimental In control group $40 \%$ are male and $60 \%$ are female.

* Majority $50 \%$ belongs to first and $43.3 \%$ of children belongs to second and $6.7 \%$ of children belongs to third birth order in experimental group.

In control group majority of children $56.7 \%$ belongs to second and $40 \%$ belongs to first and $3.3 \%$ children of belongs to third birth order .

* Majority of children $53.3 \%$ belongs to rural and $46.7 \%$ belongs to urban in experimental group . In control group majority of children is $70 \%$ of children belong to rural and $30 \%$ of children belong to urban.

* Majority of children $56.7 \%$ of children belongs to nuclear family and $43.3 \%$ of children belongs to joint family and $0 \%$ of children belongs to single parent.

In control group $53.3 \%$ of children belongs to joint family and $46.7 \%$ of children belongs nuclear and only $0 \%$ children belongs to single parent.

* Majority of children $6.7 \%$ of children belongs to $<5000$ and $16.7 \%$ of children belongs to $5001-$ 10,000 and $56.7 \%$ of children belongs to $10,001-15,000$ and only $20 \%$ of children belongs to $>$ 15,000 in experimental group,

In control group $0 \%$ of children belong to $<5000$ and $3.3 \%$ of children belongs to $5001-10,000$ and $43.3 \%$ of children belongs to $10,001-15,000$ and $53.3 \%$ of children belongs to $>15,000$ rupees salary.

* Majority of children $76.7 \%$ of children belongs to Hindu and $23 \%$ of children belong to Muslim in experimental group

In control group $83.3 \%$ were Hindu and $16.7 \%$ were Muslim.

* $\quad 16.7 \%$ Children belongs to easy and $66.7 \%$ children belongs to intermediate and $16.7 \%$ of children belongs to difficult in experimental group.

In control group majority of children $20 \%$ belongs to easy and $50 \%$ of children belongs to intermediate and $30 \%$ children belongs to difficult.

* $50 \%$ children had previous exposure to hospital and 50\% children was not exposure to hospital.

In control, group majority $26.7 \%$ of children had previous exposure to hospital and $73.3 \%$ of child hadn't exposure to hospital.

* Majority children $83.3 \%$ of children were not admitted in hospital during last year and $13.3 \%$ of children's admitted once during last year and $3.3 \%$ children admitted twice in last year

In control group, $80 \%$ of children were not admitted in hospital, last year and $20 \%$ children admitted in once in last year and $0 \%$ of children admitted twice in last year. 
* $\quad 36.7 \%$ of children belong to medical diagnosis and $60 \%$ children belong to surgical diagnosis and only $1 \%$ suffers from other in the children experimental group.

In control group $56.7 \%$ belong from medical diagnosis and 43.3 belong to surgical diagnosis.

* Majority of children $100 \%$ had no any medical personnel in their family in experiments group. In control group $6.7 \%$ children was having medical personnel in their family. And $93.3 \%$ hadn’t any medical personnel in their family.

Section B: Level Of Anxiety Among Hospitalized Children Before And After Administration Of Play Therapy, In Experimental Group.

Table-1 Score interpretation of experimental group before and after giving therapy

\begin{tabular}{|c|c|c|c|c|c|c|}
\hline \multicolumn{3}{|c|}{ Experimental group pre test score interpretation } & \multicolumn{2}{c|}{ Experimental group post test score interpretation } \\
\hline \multirow{3}{*}{} & mild anxiety & $\mathrm{n}$ & $\%$ & & $\mathrm{n}$ & \multicolumn{2}{c}{} \\
\hline \multirow{3}{*}{ Valid } & 9 & 30.0 & mild anxiety & 17 & 56.7 \\
\cline { 2 - 7 } & moderate anxiety & 11 & 36.7 & moderate anxiety & 1 & 3.3 \\
\cline { 2 - 8 } & sever anxiety & 10 & 33.3 & no anxiety & 12 & 40.0 \\
\cline { 2 - 8 } & Total & 30 & 100.0 & Total & 30 & 100.0 \\
\hline
\end{tabular}

Pre and post test reveals that post test level of anxiety were lesser than pre test of study.

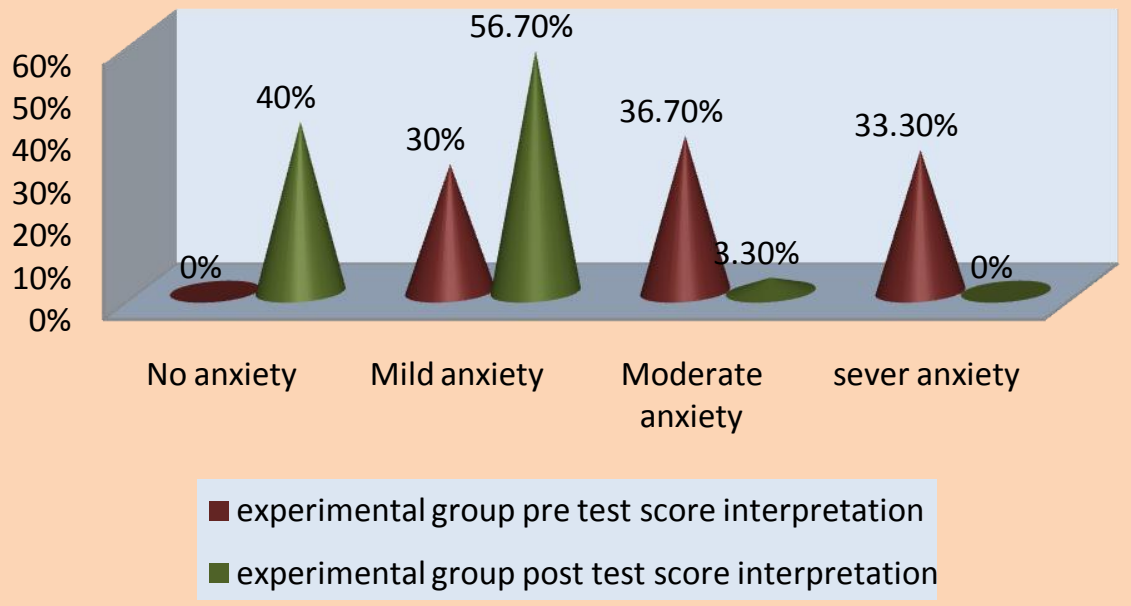

Fig 1:- Cone diagram showing pre-test and post-test anxiety level among experimental group

Table 2:- Score interpretation of pre-test score and post test score of control group

\begin{tabular}{|c|c|c|c|c|c|c|}
\hline \multicolumn{4}{|c|}{ Control group pre test score interpretation } & \multicolumn{3}{|c|}{ Control group post test score interpretation } \\
\hline & & $\mathrm{n}$ & $\%$ & & $\mathrm{n}$ & $\%$ \\
\hline \multirow{4}{*}{ Valid } & mild anxiety & 9 & 30 & mild anxiety & 8 & 26.7 \\
\hline & moderate anxiety & 13 & 43.3 & $\begin{array}{c}\text { moderate } \\
\text { anxiety }\end{array}$ & 16 & 53.3 \\
\hline & sever anxiety & 8 & 26.7 & sever anxiety & 6 & 20.0 \\
\hline & Total & 30 & 100.0 & Total & 30 & 100.0 \\
\hline
\end{tabular}

Pre and post test reveals that in post test anxiety level was not reduce much. 


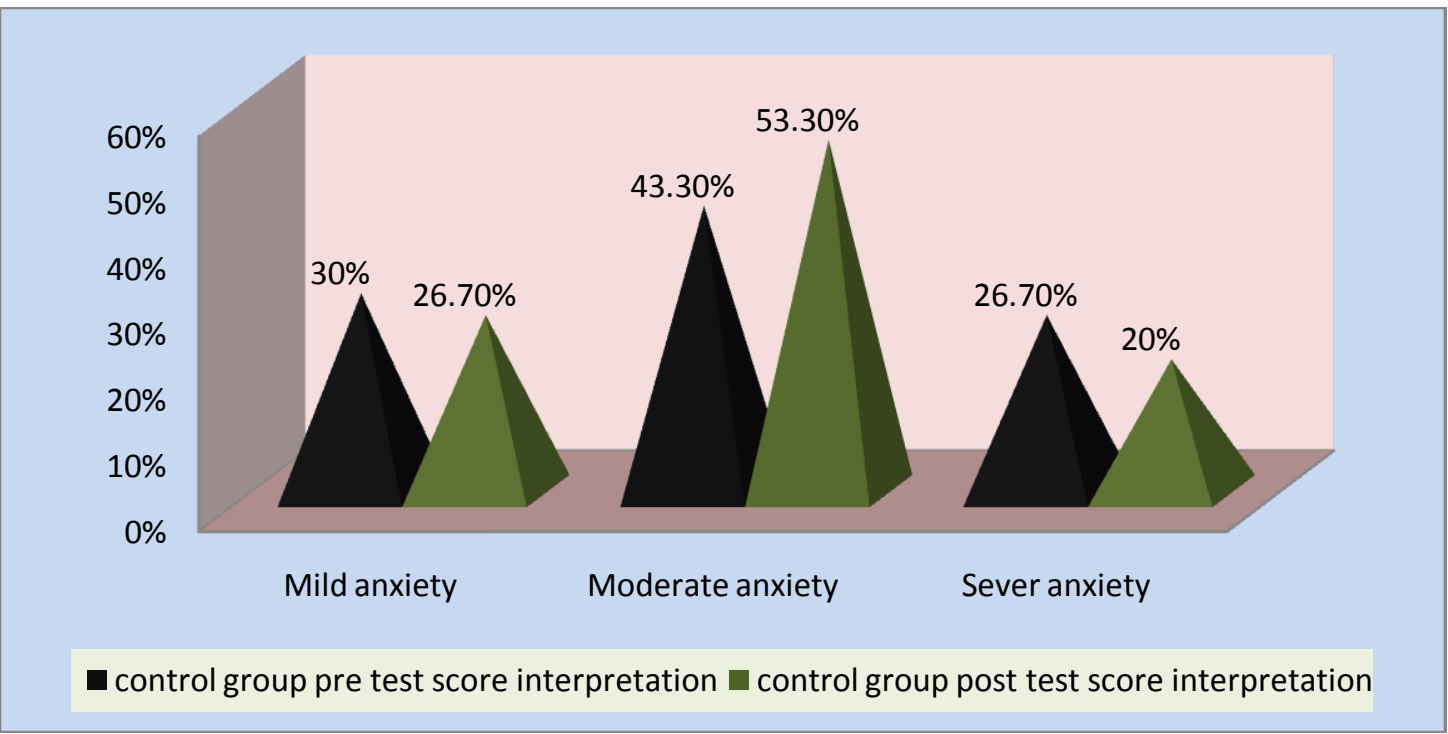

Fig 2:- Cone diagram showing pre-test and post test score interpretation of control group

\section{Section C: Analysis Of Observational Score On Effectiveness Of Play Activities On Anxiety Among Hospitalized Children}

Table 3: Analysis of observational scores in experimental group

\begin{tabular}{|c|c|c|c|c|c|c|c|}
\hline Group & Minimum & Maximum & Mean & SD & 't' value & 'p' value & Significant \\
\hline Pre test & 31 & 105 & 72.70 & 23.790 & \multirow{2}{*}{$14.015^{*}$} & \multirow{2}{*}{.000} & \multirow{2}{*}{ Yes } \\
\cline { 1 - 5 } Post test & 16 & 62 & 37.87 & 14.708 & & \\
\hline \multicolumn{78}{|c|}{ Degree of freedom $=29$} \\
\hline
\end{tabular}

The obtained ' $t$ ' value 14.015 statistically was significant at 0.000 level. So research hypothesis was accepted. So there was significant reduction in the level of anxiety among the children in experimental group.

Table - 4 Comparison of mean score of experimental post - test and control post - test.

\begin{tabular}{|c|c|c|c|}
\hline Group & Student's ' $\mathrm{t}$ ' test & 'p' value. & Mean difference \\
\hline Experimental and control group & 8.165 & .000 & 34.268 \\
\hline \multicolumn{3}{|c|}{ D.F $=29$} \\
\hline
\end{tabular}

Table 4 explained that the obtained ' $t$ ' value is 8.165 statistically value was .000 so it is significant therefore null hypothesis was rejected and research hypothesis was accepted so it clearly shows that the level of anxiety was reduce in experimental group in post test.

\section{Section D :- Association Between Selected Demographic Variables And Anxiety}

* The obtained ' $f$ ' value was 8.683 and ' $p$ ' value was 0.006 so statistically was significant so research hypothesis was accepted which implies that there was relation between age of children and anxiety.

* The obtained 'f' value was 3.873 and 'p' value was 0.045 so statistically was significant research hypothesis was accepted which implies that there was relation between Birth order of the child and anxiety.

* The obtained 'f' value was 7.988 and 'p' value was 0.002 so statistically was significant so research hypothesis was accepted which implies that there was relation between temperament of the child and anxiety.

* The obtained ' $\mathrm{f}$ ' value was 18.052 and ' $p$ ' value was 0.000 so statistically was significant so research hypothesis was accepted which implies that there was relation between Previous exposure to the hospital and anxiety.

* The obtained ' $f$ ' value was 6.204 and ' $p$ ' value was 0.019 so statistically was significant so research hypothesis was accepted which implies that there was relation between medical personnel presence among family and anxiety. 


\section{Discussion}

The Present study was undertaken to assess the level of anxiety among hospitalized children in selected hospitals at Vadodara. This chapter presents the major findings of this study and discussion in relation to similar studies conducted by other researchers.

In the experimental group pre - test score was minimum 31 and maximum 105, mean 72.70 and SD was 23.790 respectively. Where as in post test minimum score was 16 and maximum was 62 and mean, and SD was $37.87 \pm 14.708$ respectively.

In the control group Pre test score minimum was 36 and maximum was 98 and mean 76.10, and SD was 19.773 respectively. Where as in post test score minimum was 35 and maximum was 100 and mean and SD was $72.13 \pm 19.233$ respectively.

The obtained ' $t$ ' value 14.015 statistically was significant at 0.000 level. $(<0.05)$ So research hypothesis was accepted. So there was significant reduction in the level of anxiety among the children in experimental group

\section{Conclusion}

In the experimental group pre - test score was minimum 31 and maximum 105, mean 72.70 and SD was 23.790 respectively. Where as in post test minimum score was 16 and maximum was 62 and mean, and SD was $37.87 \pm 14.708$ respectively.

In the control group Pre test score minimum was 36 and maximum was 98 and mean 76.10 , and SD was 19.773 respectively. Where as in post test score minimum was 35 and maximum was 100 and mean and SD was $72.13 \pm 19.233$ respectively.

The findings shows that children's was anxious in the pre-test and were as in the post-test shows that children's was not anxious or reduced anxiety so, it indicates that play activities was effective.

The ' $t$ ' test which was computed between pre-test and post-test scores indicated that there was a reduction in the level of anxiety among the hospitalized preschool children. Hence it was concluded that play activities was effective method to reduce the anxiety.

\section{Acknowledgement}

I extend my heartfelt gratitude to all for their prayers, support and best wishes which has enabled me to carry out this study.

\section{Nursing Implications}

Nursing implication the nursing implication of the study could be discussed under nursing service, nursing education, nursing research and nursing administration.

\section{Nursing Practice}

$>$ Nurses play a critical role in help in the child and family to cope effectively with hospitalization through play activities.

\section{Nursing Education}

$>$ To provide play activities to the children nurse should have adequate knowledge regarding play activities. Nursing education programme should incorporate this factor in the nursing curriculum.

\section{Nursing Administration}

$>$ Nurse administrators are the backbone for providing facilities to re provide. Play activities to reduce anxiety among hospitalized children. There should be a provision for nurses to devote time for giving play activities to reduce anxiety in the hospitalized children.

\section{Nursing Research}

$>$ Nurses being the largest groups in the health care delivery system and being more close to patients, should take initiative to conduct further research regarding Play activities and provide correct information to reduce anxiety among hospitalized children.

\section{Recommendation}

$>$ On the basis of the study that had been conducted, certain suggestions are given for future studies

$>$ Similar study may be replicated on large sample.

$>$ A comparative study may be conducted between rural children's and urban children's.

$>$ A case study may be conducted on quality of life among hospitalized children. 
Similar study can be conducted without using control group.

\section{References}

[1]. Ingalls, saleroom. Maternal and child health nursing. 9th edition. Network: Mosby; 1999.

[2]. Sadler C. child's play nurses times. 1990; 86 (11): $16-17$.

[3]. Saucier Bl. Play activities a nursing intervention. Advanced clinical care. 1989.

[4]. Ziegler Debbie Michelle. Preparation for surgery and adjustment to Hospitalization. Nurses clinician of North America. 1994; 29 (4):655-59.

[5]. Willam.A. Rae etal. The Psychosocial Impact of Play in Hospatalised Children. 2002; Oct 2.

[6]. Boland. Play Therapy. 2000; Feb: 23. 